\title{
Afinal, O QUE QUEREM aS MUlHeres? MATERNIDADE E MAL-ESTAR
}

Silvia Alexim Nunes*

\section{Resumo}

$\mathrm{O}$ artigo pretende mostrar que a pergunta de Freud "O que quer a mulher?" permanece pertinente ainda hoje, na medida em que reflete o mal-estar relativo aos impasses colocados pelas escolhas e desejos femininos que extrapolam o ideal materno. Analisa o contexto histórico no qual foi formulada, procurando enfatizar as diferenças e as permanências em relação à condição feminina nos dias atuais, quando a pergunta faz sua reentrada na cena social.

Palavras-chave: maternidade; feminilidade; desejo; conflito; Freud.

\section{Abstract}

After all, What Do WOMEn WANT? MOtherhood AND ITS Discontents

The aim of this article is to demonstrate that Freud's question about "What does a woman want?" is still relevant, as it reveals the discontents about the impasses brought up by females choices and desires that surpass the motherhood ideal. We analyse the historical context in wich the question was formulated emphasizing the differences and the similarities in nowadays females social conditions, when the question reappears in the social scene.

Keywords: motherhood; femininity; desire; conflict; Freud.

\section{INTRODUÇÃo}

A pergunta que dá título a este artigo, "Afinal, o que querem as mulheres?", foi o tema de uma série de televisão e de uma mesa redonda para a qual fui convidada a participar, organizada pelo Departamento de Psicologia da PUC-Rio,

* Psicanalista. Doutora em Saúde Coletiva (IMS/UERJ). 
em parceria com a Globo Universidade. Logo de início, me chamou a atenção o fato de a pergunta estar formulada no plural. Isto porque essa pergunta remete a outra, feita por Sigmund Freud há mais de 80 anos, só que no singular. A pergunta freudiana se tornou clássica e uma bússola para a psicanálise no que concerne às articulaçôes teóricas em torno da mulher e da feminilidade. No entanto, em função de seu caráter instigante, extrapolou o campo psicanalítico, ressurgindo em outras áreas de saber, permanecendo viva até nossos dias.

Essa passagem do singular para o plural não se deu por acaso. Ela é tributária das mudanças, ocorridas nos últimos cem anos, relativas ao lugar social e à inserçáo das mulheres na cultura ocidental moderna. Aponta que o sexo feminino deixou de ser percebido a partir de um modelo único, o materno, instituído como ideal desde a modernidade e no qual Freud esteve imerso ao longo de seu percurso.

Se a pergunta formulada no plural aponta uma novidade, o fato de vir introduzida pela exclamação Afinal aponta, ao contrário, uma permanência: a perplexidade, a dúvida e a ansiedade provocadas pelo querer feminino ao longo dos últimos duzentos anos.

Freud dirigiu essa pergunta a Marie Bonaparte, sua analisanda e discípula dileta, formulando-a com uma boa dose de desânimo e espanto. Sentia-se diante de uma espécie de "enigma" que não conseguia desvendar: "A grande pergunta que não foi nunca respondida e que eu não fui capaz ainda de responder, apesar de meus trinta anos de pesquisa sobre a alma feminina é - O que quer uma mulher?" (Bertin, 1989: 250).

Após trinta anos de estudos sobre a alma feminina, este homem e psicanalista dirigiu sua pergunta a uma mulher, também psicanalista. Portanto, uma pergunta de um homem perplexo a uma mulher que deveria, a partir de sua própria experiência, trazer novas luzes ao que denominou de continente negro da psicanálise (Freud, 1977 [1926]). Não a uma mulher comum, mas a uma que considerava diferenciada, supondo ser mais capacitada a refletir sobre seu dilema em torno do feminino por ter ousado, naquela época, correr atrás de seu desejo e tornar-se psicanalista.

Freud interessou-se pela mulher e sua sexualidade ainda no início de seu percurso como psicanalista. Desde os seus "Estudos sobre a histeria" (1977 [1893-1895]) até "Análise terminável e interminável” (1997 [1937]), ao longo de quarenta e quatro anos, pensou e refletiu sobre a feminilidade, desenvolvendo diferentes perspectivas. Suas elaborações são de extrema riqueza, embora cheias de contradiçôes e conflitos. Com isso, vão levá-lo a se declarar inseguro em relação às suas teorias em sua conferência sobre a feminilidade em 1932. É nesse contexto tardio de sua obra que sua famosa pergunta - O que quer uma mulher? - pode 
ser feita. Uma pergunta que, formulada após tantos anos de estudos, revelava, a meu ver, os impasses da condição feminina diante da permanência das expectativas sociais em torno da maternidade, ainda na década de 1930 (Perrot, 2007). Um questionamento que ressaltava a insuficiência das teorias da época, inclusive de suas próprias, para dar conta dos conflitos femininos. No entanto, com essa pergunta, Freud colocou em questão as teorias científicas que circunscreviam o desejo feminino à maternidade e à vida doméstica.

As teses freudianas sobre a mulher e sua sexualidade são tributárias de uma determinada concepção sobre o feminino, elaborada na aurora da modernidade europeia, que marcou as sociedades ocidentais. Concepçáo que Freud adotou de início, mas que problematizou ao longo de seu percurso, na medida em que sua experiência clínica apontava os impasses resultantes do confronto entre essa concepção e as aspiraçôes e desejos das mulheres em suas vidas.

\section{MULHER E MATERNIDADE: A CONSTRUÇÃO DE UMA EQUIVALÊNCIA}

Foi durante os séculos XVIII e XIX, no bojo da constituição da ordem familiar burguesa, que a mulher se tornou objeto de grande interesse médico. A partir da preocupação com a mortalidade infantil e com o aperfeiçoamento da formação física e moral das crianças, a medicina ocidental descobriu a importância da relação mãe e filho. A mãe foi, então, considerada uma figura privilegiada e principal responsável pelos cuidados com a prole. É nesse contexto que, com argumentos calcados na biologia, os médicos passaram a defender a fixação da mulher à funçáo materna, ao lar e ao casamento. Eles buscam naturalizar e caucionar, através de sua racionalidade científica, a dominação da mulher pelo marido, num projeto político que lhes fechava as portas para qualquer outra forma de inscrição social (Schiebinger, 1991).

No entanto, esse movimento de circunscrever a vida feminina à esfera privada entrou em contradiçáo com o modelo de sociedade liberal e igualitária emergente naquele momento. Os arautos desse novo projeto político se depararam com um impasse. No modelo familiar burguês, para que a mulher pudesse exercer adequadamente sua tarefa, era preciso uma dedicação total. Ela deveria ter sua vida restrita ao lar e à maternidade e para tal lhe eram negados o espaço público e o estatuto de cidadã. Ora, como justificar a dominação da mulher pelo homem, sua exclusão da esfera pública e as diferenças sociais entre os dois sexos, se, de acordo com os ventos liberalizantes da ordem burguesa nascente, todos deveriam ter os mesmos direitos? Esse dilema foi resolvido pela ancoragem da diferença sexual e cultural 
dos sexos em uma biologia da incomensurabilidade, na qual homens e mulheres foram pensados como radicalmente diferentes (Laqueur, 1987). A reinterpretaçáo do corpo feminino e da diferença entre os sexos foi a maneira encontrada de restabelecer, num outro registro, a hierarquia entre homens e mulheres. Vemos surgir, então, uma ligação fundamental entre o sexo feminino e a maternidade, inexistente até aquele momento, com a construção da ideia de instinto materno (Badinter, 1985).

Até o século XVII, as mulheres não eram responsáveis pela sobrevivência e pela educação dos filhos e nem convocadas a assumir uma função de maternagem. Ao contrário, a concepção sobre a mulher que prevaleceu até aquele momento era bastante negativa. Esta foi herdada do cristianismo primitivo, que concebia o sexo feminino como mais carnal, dotado de sentimentos maléficos e de um desregramento sexual ameaçador (Dalarum, 1990). O cristianismo estabeleceu uma relação entre o feminino, o sexo e o mal. Até a Idade Média e o Renascimento a mulher aparece como uma figura perigosa e diabólica, mais inclinada à luxúria e aos excessos sexuais, portadora do mal e da morte (Richards, 1993). É essa concepção que filósofos, médicos e moralistas do século XVIII vão tentar modificar.

No momento em que se propóe que a mulher deve ser a guardiá da família e da infância, coloca-se, porém, um grande problema: como delegar uma responsabilidade tão grande a um ser táo desqualificado? É nesse contexto que vemos surgir toda uma preocupação com a educaçáo feminina. Ao mesmo tempo começa a ser construída uma imagem positiva da mulher, que passa então a ser vista como sensata, modesta e ponderada, cujas ambiçôes não ultrapassariam os limites do lar (Rousseau, 1992 [1762]). Transformar a mulher em mãe foi um processo que determinou uma reformulaçáo profunda da imagem do sexo feminino característica das sociedades europeias até aquele momento. Isto demandou um apelo à ciência médica, que foi chamada a colaborar para descrever o que era uma mulher (Nunes, 2000).

Essa modificação da visão sobre o sexo feminino vai se fazer paralelamente ao estabelecimento de uma nova concepçáo sobre a diferença entre os sexos. Segundo Thomas Laqueur (1989), é no século XVIII que a diferença entre homens e mulheres começa a ser pensada como uma derivação direta da diferença sexual. É nesse momento que se faz uma vinculação entre a diferença morfológica entre os sexos e diferença de gêneros, construindo-se novos ideais de feminilidade e masculinidade. Até o século XVII, a visão dominante sobre o sexo feminino e a diferença sexual era a mesma da Antiguidade, quando o sexo feminino foi descrito como homólogo ao masculino. Essas ideias se apoiavam, sobretudo, no pensamento de Galeno, que durante muito tempo foi hegemônico no Ocidente (Foucault, 1984).

Psic. Clin., Rio De Janeiro, vol.23, N.2, P.IOI - II 
Galeno pensava a mulher como um homem que tinha os órgáos sexuais invertidos. Para ele, a mulher possuía os mesmos órgãos que o homem só que para dentro. Essa inversão se daria pelo fato de o sexo feminino ser dotado de menor quantidade de calor corporal. O homem seria mais perfeito por ser mais quente e a mulher, mais fria, sua versáo imperfeita. Na concepçáo de Galeno era o calor que determinava a diferença de sexos. Não havia, portanto, uma diferença de essência entre homens e mulheres. Estas poderiam até virar homens, aproximando-se da perfeição, caso houvesse um aumento de calor. Nesse modelo, não havia a ideia de que era a diferença anatômica entre os sexos que determinava o gênero de uma criança. Aqui, o fator determinante da diferença de gêneros era a quantidade de calor presente no corpo humano. Supunha-se, então, uma essência única para os dois sexos e os médicos consideravam que havia apenas uma estrutura básica para o corpo humano: o homem branco europeu (Laqueur, 1987).

É somente no século XVIII, a partir da necessidade de redefinir a posição da mulher na família e na sociedade europeia, que se observa uma nova forma de pensar a diferença entre os sexos e paralelamente uma nova concepção sobre a mulher. À medida que a maternidade aparece como um ideal, os médicos vão rejeitar a imagem do sexo feminino como imperfeito e passam a olhá-lo como sexualmente perfeito; o útero é considerado um órgão nobre e característico da mulher. $\mathrm{O}$ corpo feminino vai passar a ser tratado como possuindo características específicas, que determinariam sua vocação para a maternidade.

O estudo de Londa Schiebinger (1987) sobre a modificação da descrição do esqueleto feminino na passagem do século XVII para o século XVIII é exemplar desse processo. Ela propóe que, na tentativa de redefinir a posição da mulher na sociedade europeia, as primeiras representaçóes científicas do esqueleto feminino apareceram. Tais representaçôes valorizavam as partes do corpo feminino politicamente significativas. Assim, desenhava-se a mulher com menor crânio (sinal de menor aptidão intelectual) e maior pélvis (sinal de maior aptidão para a reproduçáo). Os primeiros desenhos do esqueleto feminino surgiram carregados de valores, auxiliando na produção dos ideais de masculinidade e feminilidade emergentes. Os anatomistas "melhoraram" a natureza para adequá-la a esses ideais.

Observa-se um processo delineador minucioso das diferenças existentes entre homens e mulheres. Os discursos médicos demonstram insistentemente a existência de diferenças consideráveis no corpo, nos ossos, nos nervos, na alma, em todos os aspectos físicos e morais. Começa a prevalecer a ideia de que existiria uma diversidade biológica entre os dois sexos. A consequência lógica desse percurso foi a consolidação da ideia de uma diferença de essências, naturalmente determinada, que passou a justificar inserçôes sociais diferentes para homens e 
mulheres. A esfera de atuação feminina seria a esfera doméstica; a masculina, a esfera pública.

É interessante observar que tanto o romantismo de Rousseau quanto o ideário iluminista defendiam essa proposta de encerramento da mulher no lar (Badinter, 1991). Para que esse nascente ideal feminino não entrasse em conflito com os ideais igualitários que defendiam, esses pensadores formularam e subscreveram um perfil feminino ancorado em uma suposta essência naturalmente determinada, que acabou por negar às mulheres o estatuto de cidadâs. Com o argumento de que a mulher não era nem inferior nem imperfeita e sim perfeita em sua especificidade. Descreviam-na como dotada de características físicas e morais específicas de seu sexo e condizentes com a função materna e a vida doméstica; o oposto do homem, que seria mais apto à vida pública, ao trabalho e às atividades intelectuais. Não propunham uma relação de inferioridade e sim de complementaridade. Apontavam, então, como características da essência feminina, atributos como: fragilidade, doçura, afetividade, passividade e capacidade de sacrifício. Características consideradas fundamentais para o cuidado com a infância. Associa-se a maternidade e a feminilidade a uma ética do cuidado com o outro. A educaçáo das meninas deveria estar voltada para a formaçáo de um caráter dócil e passivo, condiçáo para o sucesso do casamento e da vida familiar (Rousseau, 1992 [1762]).

Durante o século XIX essa preocupação em delimitar as diferenças entre os sexos se ampliou cada vez mais. Procurava-se demonstrar nos corpos e nas almas essas diferenças, chegando a mínimos detalhes através dos quais se justificava a desigual inserção social de homens e mulheres. Com esse discurso naturalista, procurava-se caucionar as desigualdades sociais. Assim, a preocupação em adestrar o corpo e a sexualidade feminina, com vistas à procriaçáo e ao casamento, é constante e intensa. Qualquer desejo ou comportamento sexual que extravasasse esses limites era tratado como um "excesso", como produto de uma degeneração psíquica, como uma patologia (Nunes, 1991). No centro desse debate, aparece uma preocupação clara com o desejo e a sexualidade feminina percebidos como ameaça à espécie e à ordem social.

Tornava-se imperioso disciplinar esses desejos ameaçadores a fim de minimizar os riscos de desregramento e maximizar sua potencialidade geradora, reprodutiva e cuidadora. Nesse contexto ganha força a imagem da histérica enquanto figura emblemática da possibilidade de desregramento, à qual estaria exposta toda mulher, mas também enquanto personagem rebelde e que denunciava as contradiçóes nas quais estava inscrita (Cattoné, 1992).

Foi com essas mulheres histéricas que Freud se deparou em sua clínica. Mulheres que apresentavam dificuldades em se adaptar ao ideal feminino oitocentista 
e que, diante da coerção estabelecida ao seu corpo, à sua sexualidade e à sua vida de modo geral, encontravam nos sintomas histéricos uma forma de dramatizar sua insatisfaçáo e seu protesto. Os tratamentos psiquiátricos, com todas as duchas frias e demais corretivos, não foram capazes de esfriar os ânimos dessas mulheres, que acabaram chegando às mãos e aos ouvidos de Freud.

\section{O encontro de Freud com as histéricas}

No início de suas pesquisas, Freud não só adotou a concepção hegemônica nos séculos XVIII e XIX - que pressupunha homens e mulheres naturalmente diferentes e complementares - como compartilhou e foi defensor do ideal feminino que valorizava uma imagem de mulher passiva e maternal, cuja vida deveria ficar restrita à esfera doméstica (Gay, 1989). Contudo, à medida que ouvia suas pacientes histéricas dava-se conta de que a economia libidinal feminina não podia ficar restrita à precária possibilidade de realização determinada pelo papel que lhe era designado. $\mathrm{O}$ confronto com o desejo dessas mulheres abalava o pressuposto da ciência da época - de uma essência feminina materna e passiva.

Os relatos de casos das suas primeiras pacientes histéricas, aí incluindo o tratamento de Anna O., por Breuer, são exemplares da contradição na qual as mulheres oitocentistas estavam inscritas. São documentos preciosos a partir dos quais podem ser ressaltados aspectos relevantes sobre a vida dessas mulheres. É notável a dificuldade que encontravam para se constituir como indivíduos autônomos e singulares, numa sociedade em que o feminino era desqualificado no confronto com o masculino, e o desejo da mulher deveria ser recalcado, permanecendo na dependência do desejo do homem. Desde o início aparecem claramente os componentes sociais da patologia em que a mulher estava implicada. Assim, por exemplo, Anna O. foi descrita como uma moça frustrada em seus anseios intelectuais, cuja vida se tornava bastante empobrecida, que tentava dar colorido a uma existência monótona através de seus devaneios. Esses devaneios constituíam a forma possível de experimentar sentimentos e emoçóes que não lhe eram possibilitados na vida cotidiana. A necessidade de esconder essas fantasias demonstra o quanto elas eram incompatíveis com o ideal doméstico de feminilidade imposto. Aliás, Breuer não se furta a alocar como causas predisponentes da doença dela a vida familiar monótona e a ausência de atividade intelectual adequada, que a deixaram com um excedente não utilizado de vivacidade e energias mentais, cuja única alternativa de satisfação foi lhe dada pela força de sua imaginação, por 
seu teatro privado, que acabou por lançar as bases para uma dissociação mental (Breuer \& Freud, 1977 [1893-1895]).

Como assinala Paul-Laurent Assoun (1993), os relatos de Freud apontam para um quadro social no qual a mulher aparece aprisionada a uma rede familiar da qual é inteiramente dependente e em relaçáo à qual fica em muitos momentos desprotegida. Confinadas ao espaço doméstico, essas mulheres tinham pouca ou quase nenhuma possibilidade de viver seus anseios e fantasias, sexuais ou não. Ficavam restritas aos personagens e acontecimentos que marcassem esse pequeno mundo, no qual deviam ancorar seus desejos e expectativas.

No caso de Elizabeth, por exemplo, a descrição de Freud da inserção da jovem no universo familiar é bastante ilustrativa. Mais jovem de três filhas, era ternamente ligada aos pais. A saúde de sua mãe era frágil, o que a levou a estabelecer um contato mais próximo com o pai, um alegre homem das rodas mundanas, que costumava dizer que aquela filha tomava o lugar de um filho e de um amigo com quem podia trocar impressóes. A relação com o pai era um estímulo intelectual para a jovem, que queria estudar ou receber uma educação musical e estava indignada por ter de sacrificar suas inclinaçôes e sua liberdade de julgamento pelo casamento (Breuer \& Freud: 1977 [1893-1895]). É interessante apontar que tanto o pai como Freud rotulavam essas aspiraçóes como masculinas. $\mathrm{O}$ pai por acreditar que a filha se afastava do ideal de feminilidade e Freud porque lia suas aspiraçôes como um descontentamento por ser mulher. Ambos acreditavam, portanto, que uma mulher devia ter como vontade suprema o casamento e a vida familiar. E, com isso, devia aceitar de bom grado o abandono de outros desejos e de sua possibilidade de ver e viver o mundo fora do contexto doméstico e independente da figura do marido. $\mathrm{O}$ amor, o casamento e a maternidade deveriam se constituir na única fonte de prazer e felicidade feminina. Para Elizabeth, no entanto, as coisas eram um pouco diferentes. Tendo como modelo de figura feminina uma mãe adoentada e desvitalizada, restava-lhe como possibilidade identificatória o pai, cuja vida alegre e colorida estava mais de acordo com suas expectativas. Aspirar ser como a mãe era conformar-se com uma vida monótona e sem graça. Ser mulher nessas circunstâncias não lhe parecia um destino muito alentador. $\mathrm{O}$ mundo paterno, a vida pública eram apelos dos quais não se conformava em abrir mão.

Após a morte do pai, a vida de Elizabeth sofreu grandes mudanças. Sua família ficou reduzida à mãe e às irmãs, que passaram a viver num certo isolamento. Isto significou a interrupção brusca das relaçôes sociais que lhe proporcionavam diversão e interesses variados. Elizabeth viu-se, então, limitada ao círculo familiar, às tarefas 
domésticas e aos cuidados com a mãe doente que tanto lhe pareciam limitados e limitadores. Nessas circunstâncias, sua tentativa de restaurar a felicidade perdida foi bastante de acordo com o modelo de feminilidade mais facilmente aceito: colocou o marido da irmá como objeto de seu desejo e ser amada por esse homem, como uma finalidade possível para sua vida. No restrito universo doméstico, o cunhado apareceu como o único alento para sua infelicidade. $O$ fato de este amor ser impossível colocou a jovem diante de um conflito que não poderia ser superado, determinando a eclosão de sua doença.

O caso de Elizabeth coloca em evidência o impasse vivido pelas mulheres que não se satisfaziam com o torniquete que lhes era imposto pela organização dos papéis sociais femininos e masculinos, na medida em que lhes era vedado o acesso à vida pública e a qualquer ideal de emancipação. A liberdade de desejar não era uma alternativa aberta a essas mulheres que, no entanto, denunciavam suas frustraçóes através de seus sintomas.

A histeria feminina foi uma forma ativa e, sobretudo, barulhenta através da qual as mulheres reagiram às exigências que lhes foram colocadas. Como bem mostra Emilce Dio Bleichmar (1988), existe um "feminismo espontâneo" na histérica que consiste num protesto desesperado, aberrante, atuado de quem reivindica a possibilidade de ser mulher sem ser reduzida a um único modelo de feminilidade: a maternidade.

Freud inaugurou a psicanálise a partir da escuta dos sintomas histéricos de suas pacientes. Suas teses modificaram significativamente a concepção sobre a histeria hegemônica nos discursos médicos do século XIX. A partir dele, a histeria deixou de ser pensada como produto de uma disfunçáo corporal para se converter no efeito de um fantasma sexual. Freud subjetivou o desejo sexual, arrancando-o de sua suposta base animal, demonstrando que a histérica adoece devido à repressáo desse desejo. Nesse sentido a histérica, para Freud, era uma vítima da civilização e deveria ter seu sintoma compreendido e não reprimido. Assim, apontou a opressão sexual à qual as mulheres estavam submetidas, e a histeria como consequência desse fato (Freud, 1977 [1908]).

No entanto, ao priorizar o lugar da sexualidade no sintoma histérico, Freud deixou de realçar outro aspecto que salta aos olhos em seus casos clínicos: que essas mulheres encontravam-se extremamente insatisfeitas com o papel e o lugar que a sociedade lhes reservava. Preso a concepçáo iluminista da diferença entre os sexos, aceitou como fato consumado e coerente com os desígnios da natureza a desigualdade real existente entre homens e mulheres, como deixou claro à sua esposa em sua correspondência de amor (Freud, 1982). Uma cegueira que o im- 
pediu de perceber o protesto histérico também como uma reivindicação, mesmo que inconsciente e conflitada, de liberdade para desejar.

Paralelamente, sua teoria sobre a sexualidade feminina reforçou a assimilação da feminilidade à maternidade. Suas elaborações vão levá-lo a uma concepçáo do desenvolvimento da sexualidade feminina na qual a maternidade aparece como o único destino desejável e normal para as mulheres (Freud, 1977 [1931]). Ao longo de seu percurso, Freud propôs uma teoria da sexualidade que desvinculou o processo de sexuação de homens e mulheres da anatomia e da biologia e, portanto, de uma perspectiva naturalista e essencialista, tratando-o como um processo de elaboração psíquica. Para Freud, seria a elaboração do complexo de castração que possibilitaria a constituição de uma identidade masculina ou feminina.

No entanto, no que diz respeito ao sexo feminino suas consideraçóes tropeçavam no ideal feminino materno predominante ainda nas primeiras décadas do século XX. Considerava, entâo, que existiam três resultados possíveis da passagem das mulheres pela experiência da castração, dependendo de se esta passagem fosse bem-sucedida ou não. Assim, o resultado poderia ser: uma inibição da sexualidade, que levaria à neurose; uma fixação em uma posiçấo viril, que negaria a feminilidade, e a maternidade, que pressupunha como única posiçáo normal e desejável para a mulher. Portanto, sua teoria, embora caminhasse na contramão de uma perspectiva naturalista em relaçáo ao desejo de um filho, não escapava à definição reducionista do feminino, descrevendo o tornar-se mulher como uma espécie de "vocação libidinal" para a maternidade.

As teses freudianas sobre a sexualidade feminina causaram, com razão, muita polêmica tanto no âmbito da própria psicanálise quanto fora dela. Não nos cabe aqui retomá-las e sim sublinhar que essa polêmica reverberou em Freud, que demonstrou seu mal-estar com sua famosa pergunta $O$ que quer uma mulher?. Um questionamento que, como já assinalamos, se colocou para ele bastante tardiamente. Não por acaso em 1932, em sua conferência "Feminilidade", explicitou sua insatisfação com suas pesquisas remetendo a possibilidade de elucidação do enigma feminino ao futuro da ciência, aos poetas e à experiência de cada um.

Ao se perguntar sobre o querer feminino, colocou em relevo a capacidade desejante das mulheres, capacidade até entâo ora negada pelo ideal passivo - materno -, ora estigmatizada como desviante a esse mesmo ideal. Tal capacidade era a condição de possibilidade para a invenção de novas formas de subjetivação para além do restrito ideal materno. Assim, ao interrogar-se sobre o desejo feminino, Freud descortinou, ao final de seu percurso, novos horizontes para a questâo feminina e a feminilidade (Birman, 1996). 


\section{SOBRE DESEJO E QUERER}

Para a psicanálise, um desejo não é algo inato, que existe pronto e formulado a priori no íntimo do sujeito. O desejo é movimento, uma moção pulsional, sempre em busca de satisfação, de prazer, de uma vivência de completude. Freud denominou de desejo uma corrente que começa com o desprazer e visa o prazer, formulando-o como uma tentativa de restaurar uma experiência de satisfação que ponha fim a um estímulo interno excessivo. Afirma ainda que só um desejo é capaz de colocar o aparelho psíquico em movimento (Freud, 1977 [1900]).

Para a psicanálise, portanto, o desejo é o que sustenta a vida, o que move o sujeito para a vida. Essa moção para a vida é uma potencialidade que permite ao sujeito querer alguma coisa, mas não é de imediato um querer. O desejo é condição de possibilidade para o querer. Mas o desejo só se torna um querer específico dentro da história emocional de cada um, que é vivida, por sua vez, em um determinado contexto histórico e cultural.

O desdobramento do desejo em um querer é um processo absolutamente singular que não é determinado pela natureza ou pela biologia, nem por nenhuma essência. Trata-se de um trabalho de elaboração psíquica que se dá em diferentes registros do psiquismo, conscientes e inconscientes, e que depende da experiência do indivíduo, de suas vivências de prazer e desprazer, da forma como ao longo da vida essas vivências foram e são percebidas pelo próprio sujeito e por aqueles que o cercam, e ainda das condiçóes sociais e culturais em que essas vivências se dão.

Nos dias de hoje, a ampliação do horizonte feminino para além da esfera doméstica abriu novas possibilidades subjetivas e expectativas de vida para as mulheres. As conquistas políticas obtidas pelos movimentos feministas que garantiram direitos iguais para homens e mulheres foram certamente os motores dessas mudanças. As mulheres passaram a poder transformar sua capacidade desejante em quereres múltiplos e diversificados.

O advento da pílula anticoncepcional permitiu de forma mais eficaz que as mulheres possam decidir se querem e quando querem ter filhos. A maternidade, identificada na modernidade como condição natural feminina e ideal principal a ser alcançado, deixou de se sustentar enquanto tal para boa parte das mulheres. Porém ainda é fonte de grandes conflitos. Tais conflitos dizem respeito tanto à vivência singular de cada mulher quanto à sua relaçáo com aqueles que a cercam e a sociedade.

Não por acaso, a pergunta retorna ao centro da cena social, ganhando destaque na mídia. Só que retorna agora no plural: afinal, o que querem as mulheres? Pergunta que, se traz implícito o reconhecimento de que as mulheres não formam 
um conjunto único, revela ainda uma perplexidade: o que elas querem, afinal? Um mal-estar diante dos diferentes "quereres" das mulheres na contemporaneidade, nem todos vistos com bons olhos.

\section{Afinal, o QUe QUerem aS MUlHeres?}

Se o paradigma que associou feminilidade e maternidade hoje não é mais suficiente para definir as mulheres, ele ainda está presente no imaginário social sobre o sexo feminino. Apesar da abertura para novas perspectivas, permanece poderosa a ideia de que uma mulher só se realiza plenamente com a maternidade.

Surge então um novo ideal de mulher, aquela que consegue conciliar seus desejos com todas as exigências sociais colocadas sobre ela. Ser bonita, magra de preferência, bem-sucedida profissional e financeiramente ao mesmo tempo que mãe e esposa dedicada. Esse ideal plasma a imagem do que se convencionou chamar de "mulher contemporânea".

Mas, afinal, quem é a "mulher contemporânea"? A executiva que comanda uma empresa? A mulher do campo? A mulher que opta por dedicar sua vida aos cuidados com os filhos e à família? A mulher que procura conciliar profissão e maternidade? A mulher que decide não ter filhos? A mulher aprisionada à ditadura do corpo? A adolescente grávida? A mulher solteira? A lésbica? Essa pequena relação mostra que são infinitas as formas de se inscrever em nossa cultura como mulher. E o novo modelo ideal forjado para a mulher contemporânea tende a uniformizar o feminino em torno de um projeto massificante, apagando as diferenças e constituindo-se em um novo torniquete. Um ideal que, embora mantenha as portas abertas para o trabalho feminino, permitindo assim que essa metade da população se torne consumidora, ainda privilegia a funçáo materna, sustentando o paradigma que associou feminilidade e maternidade.

Considera-se que determinados valores associados à maternidade e à feminilidade são as verdadeiras qualificações femininas para o bom desempenho na vida e no mundo. Um exemplo claro da força desse tipo de discurso foi o que se pôde observar em nossas últimas eleiçóes presidenciais: duas candidatas mulheres que tiveram frequentemente exaltados, como grandes credenciais para o cargo, valores associados à maternidade. Uma foi apresentada como a futura "Mãe do Brasil", uma mulher capaz de cuidar dos mais desamparados. A outra, por sua ligação aos movimentos ecológicos, teve sua luta em defesa da natureza associada a uma maior capacidade pessoal de preservação e de cuidado com o povo e a nação: a ética da maternidade e do cuidado recuperada, agora, como qualidade fundamental das 
candidatas para o exercício da presidência da República. A maternidade e os valores a ela associados são, portanto, ainda hoje, considerados expressão por excelência do feminino e do que as mulheres teriam de melhor.

Mais do que uma permanência podemos perceber um crescente resgate da ideia de que o sexo feminino traz em si uma vocação para a maternidade. Elizabeth Badinter chama a atençâo para uma revolução silenciosa que se operou nos últimos anos, principalmente na Europa. Esta tem como um de seus objetivos recuperar uma naturalização da associação maternidade / feminilidade, que foi amplamente questionada e criticada pelos estudos de gênero e pelas lutas feministas das décadas de 1960 a 1980. Naturalização que considera um entrave às reivindicaçôes femininas por igualdade de direitos (Badinter, 2010).

Propõe que as oscilações e inseguranças causadas pelas crises econômicas da última década, associadas a uma crise identitária provocada por uma maior indiferenciação dos universos masculino e feminino, são um caldo de cultura importante para fertilizar esta nova redução do feminino à maternidade. Para justificar tal reducionismo, recorre-se à velha e boa natureza, tendo como fundamento a ideia de instinto materno. A consequência mais visível dessa estratégia é que as mulheres acabam tendo mais uma vez sua identidade atrelada ao ideal da boa mãe e com isso sendo levadas a assumir a maior parte das tarefas domésticas e dos cuidados com os filhos no que se convencionou chamar "dupla jornada" de trabalho.

Ao final dos anos de 1970 detentoras dos meios de controlar sua capacidade reprodutiva, as mulheres puderam aspirar novas formas de vida. Puderam, a partir de então, escolher entre dar prioridade as suas ambiçóes pessoais, gozar do celibato ou de uma vida de casal sem filhos, ou bem satisfazer seu desejo de maternidade com ou sem atividade profissional. No entanto, como nos mostra Badinter, o retorno contemporâneo da ideia de uma natureza feminina voltada para a maternidade tempera a recém-conquistada liberdade de escolha com boa dose de culpa.

Essa culpa pode ser facilmente observada em diferentes situaçôes em que, independentemente de suas escolhas, as mulheres parecem estar sempre se medindo a partir do tal ideal contemporâneo que ou resistem em assumir, ou não se sentem capazes de realizar. Um bom exemplo, talvez o mais comum, é o da mulher sempre culpada por não corresponder às expectativas familiares e sociais enquanto mãe e esposa, seja pela dificuldade em dar conta da dupla jornada, seja por não achar muita graça em passar a maior parte de seu tempo cuidando de uma criança. Outro exemplo, cada vez mais comum, é a mulher que, casada ou não, opta por não ter filhos para dedicar-se exclusivamente a um projeto profissional. Esta também paga sua parcela de culpa, sentindo-se eternamente em dívida com a família, carregando os estereótipos de egoísta, materialista e carreirista. 
Nesse contexto, pânico, angústias, depressóes diversas derivadas dos conflitos ligados ao desejo ou não de ser mãe e à própria experiência da maternidade constituem na atualidade grande parte das demandas femininas de análise. Não é um acaso que sintomas diretamente ligados à maternidade, como as depressóes pós-parto e a denominada infertilidade sem causa aparente, sejam cada vez mais comuns na clínica psicanalítica, assim como nas clínicas ginecológicas e psiquiátricas.

Assim como as histéricas do século XIX pareciam protestar, com seus sintomas, contra o torniquete imposto pela fixação de suas vidas ao lar e à maternidade, os sintomas femininos contemporâneos parecem denunciar o mal-estar e as contradiçôes com as quais as mulheres se confrontam na atualidade, sejam elas mães ou não.

Afinal, o que querem as mulheres? Muitas e diversas coisas, certamente, mas quando damos ouvidos às suas queixas, como fez Freud com suas histéricas, descobrimos que, antes de tudo, elas querem liberdade e condiçóes que lhes permitam desejar sem precisar pagar o alto preço da culpa.

\section{REFERÊNCIAS}

Assoun, P.-L. (1993). Freud e a mulher. Rio de Janeiro: Jorge Zahar.

Badinter, E. (1985). Um amor conquistado, o mito do amor materno. Rio de Janeiro: Nova Fronteira.

Badinter, E. (1991). Condorcet, Prudhome, Guyomar... palavras de homens (1790-1793). Rio de Janeiro: Nova Fronteira.

Badinter, E. (2010). Le conflit, la femme et la mère. Paris: Flammarion.

Bertin, C. (1989). A última Bonaparte. Rio de Janeiro: Paz e Terra.

Birman, J. (1996). Por uma estilística da existência. São Paulo: Escuta.

Bleichmar, E. D. (1988). O feminismo espontâneo da histeria. Porto Alegre: Artes Médicas.

Breuer, J., \& Freud, S. (1893-1895/1977). Estudos sobre a histeria. Obras completas, ESB, v. 2. Rio de Janeiro: Imago.

Cattoné, J. P. (1992). Femmes et hysterie au XIXe siècle. Synapse, 88, 33-43. Paris.

Dalarun, J. (1990). Olhares de clérigos. In: História das mulheres: a Idade Média (pp. 2963). Porto: Ediçôes Afrontamento.

Foucault, M. (1984). História da sexualidade II - o uso dos prazeres. Rio de Janeiro: Graal.

Freud, S. (1900/1977). A interpretação dos sonhos. Rio de Janeiro: Graal.

Freud, S. (1908/1977). Moral sexual civilizada e doença nervosa moderna. Rio de Janeiro:

Psic. Clin., Rio de JANeiro, vol.23, N.2, P.IOI - II5, $201 \mathrm{I}$ 
Graal.

Freud, S. (1926/1977). A questão da análise leiga. Rio de Janeiro: Graal.

Freud, S. (1931/1977). A sexualidade feminina. Rio de Janeiro: Graal.

Freud, S. (1932/1977). Feminilidade. Rio de Janeiro: Graal.

Freud, S. (1937/1977). Análise terminável e interminável. Rio de Janeiro: Graal.

Freud, S. (1982). Sigmund Freud, correspondências de amor e outras cartas. Rio de Janeiro: Nova Fronteira.

Gay, P. (1989). Freud, uma vida para o nosso tempo. São Paulo: Companhia das Letras.

Laqueur, T. (1987). Orgasm, generation and politics of reproductive biology. In: Gallager, C., \& Laqueur, T. (Orgs.). The making of the modern body, sexuality and society in the Nineteenth Century (pp. 1-41). California: University of California Press.

Laqueur, T. (1989). Amor veneris vel dulcedo appeletur. In: Feher, M., Nadeff, R., \& Tazzi, N. Zone 5: fragments for a history of the human body (Part III, pp. 91-131). New York. Nunes, S. A. (1991). A medicina social e a questão feminina. In: Physis, Revista de saúde coletiva, 1(1), 49-76. Rio de Janeiro: IMS/UERJ/Relume Dumara.

Nunes, S. A. (2000). O corpo do diabo entre a cruz e a caldeirinha, um estudo sobre a mulher, o masoquismo e a feminilidade. Rio de Janeiro: Civilização Brasileira.

Perrot, M. (2007). Minha história das mulheres. São Paulo: Editora Contexto.

Richards, J. (1993). Sexo, desvio e danação, as minorias na Idade Média. Rio de Janeiro: Jorge Zahar.

Rousseau, J.-J. (1762/1992). Emílio ou da educação. Rio de Janeiro: Bertrand Brasil.

Schiebinger, L. (1987). Skeletons in the closet, the first illustration of the female skeleton in Eighteen Century anatomy. In: The making of the modern body (pp. 42-82). s.d.

Schiebinger, L. (1991). The mind has no sex, women in the origins of modern science. Cambridge, Massachusets: Harvard University Press.

Recebido em 5 de setembro de 2011 Aceito para publicação em 15 de outubro de 2011 